\title{
ePortfolio as a Means of Scaffolding Reflection. From Written Reflections to Graphic Narratives
}

\author{
Guillermina Gavaldon (Alcalá de Henares/Spain)
}

\section{Introduction}

This chapter is based on research centring on electronic portfolios (ePortfolios) and their potential as a means to promote reflexive and critical learning that was carried out over four years with pre-service teachers from the Faculty of Education of one of the universities in the Madrid region. Through this study, we were able to verify that this learning-and-teaching method can be an effective tool for scaffolding ${ }^{1}$ reflection, where teachers play a key role in promoting students' learning through reflection. For the ePortfolio method to be effective, however, teachers also need to direct students progressively toward self-regulated learning, and here feedback from various sources plays a key role.

According to Moon (2004), there are different levels of reflection, ranging from just describing events to those where students' reflections guide them to analyse issues, events or problematic situations from different points of view. Practices such as teacher or peer feedback have been found to promote reflection as well as in-depth thinking and learning. Students differ from one another in their

\footnotetext{
1 Although the core idea of scaffolding comes from Vygotsky's Zone of Proximal Development (a person constructs meaning through interaction with others and builds knowledge in the presence and guidance of a more knowledgeable person), Wood, Bruner and Ross (1976) relied on this concept to coin the Scaffolding metaphor. This metaphor refers to the use of reliable and temporary support or guidance by teachers or caregivers to children. As students build their knowledge, teachers and caregivers can withdraw scaffolding gradually.
} 
reflective thinking skills, and so the provision of feedback will help them to build the meaning of the learning experience and direct them to evaluate and contrast it with their prior knowledge. One of the various benefits of using ePortfolios is that they can create social environments connecting teacher-students-students. Feedback, if envisaged as a dialogue among two or more participants, serves to whet their curiosity, encourages them to think about previous conceptions and to question thought models. In this way feedback becomes a participatory method that can lead to knowledge appropriation through a transformative learning process. A further benefit of ePortfolios is that they facilitate the use of multimodal forms of communication, enabling students to use media other than writing to document their learning.

Section 2 of this paper provides more extensive background on the concepts of reflexive learning, self-regulated learning and multimodality, all of which are key affordances of the ePortfolio used in its scaffolding capacity. Section 3 describes how these principles were realised in a project in which students enrolled for teaching degrees used ePortfolios to reflect on their learning over the course of their degrees.

\section{Reflective learning, self-regulation and multimodal literacies}

\subsection{Reflection as learning}

Reflection is understood in this chapter as a cognitive process that is carried out deliberately to solve a problem, to participate in a discussion or gain more in-depth knowledge. The process should entail the interconnection of previous ideas with additional information, confronting and evaluating them and considering doubt and perplexity before issuing a judgment (Spalding \& Wilson 2002). Through reflection, a person responds to some experience, to a situation or an event that may occur during a formal class, seminar or an unforeseen event. This reflection makes a person aware of the facts they are evaluating, allowing them to conclude by expressing what they feel or think. In this sense, there are two stages of reflection, one at the time the experience is occurring, that is, reflection-in-action. The other is where a processing phase occurs, and the person thinks about it, reviews it and evaluates it at the end (Hume 2009). The way each person does this will depend on what they bring to the event: the previous knowledge which has contributed to perceiving the world in a certain way. Each person will react differently to the same learning situation, and the capacity to respond to it would depend on the degree of engagement with the activity they are performing.

The level of commitment may be related to feelings of acceptance or task rejection. Denial, for instance, might be produced due to a gap between the new experience and the previous knowledge which prevents a person from making any connections between them. Yet it is important that students make such connec- 
tions, and to help them do so, teachers must seek educational strategies that involve the students in the learning task, guiding them to think about the experience, analyse and evaluate it, either individually or in groups, but always considering the initial knowledge from which each student departs.

Using portfolios is one such educational strategy that can be used to guide reflection and develop reflective practices. The portfolio method, seen in broad terms, could be characterised according to two distinct concepts: learning and showcase. As a showcase tool, it focuses on the final product, which means that through a collection of artefacts the owner presents evidence of achievement. As a learning methodology, the key component of it is the process a learner follows to acquire a deep understanding of an issue, a problem or a task. Building this type of portfolio must be underpinned through a different level of reflection. It is here, in this reflecting process, that the students gain an understanding of a problem and this leads them to think over and revisit the difficulties, the challenges and the knowledge they have gained (Barrett 2010, Zubizarreta 2009). In Dewey's words, reflective thoughts constitute "active, persistent, and careful consideration of any belief or supposed form of knowledge in the light of the grounds that support it and the further conclusions to which it tends" (Dewey 1997: 6). It might be that some teachers consider that the best way for students to give meaning to the new information they encounter is through a systematic reflection process; however, there would be many students who do not understand what this term means or how to differentiate it from other types of thoughts (Rodgers 2002). Moon (2004) notes the differences between "reflection", "reflective learning", "reflective writing" and "reflective practice". She understands "reflection" as a process of learning and thinking. In "reflective learning" there is an intention, and it has to do with learning through reflection. The reflection process can be facilitated by the use of various media, such as writing, creating digital stories, podcasts or videos to represent it. "In making a representation of personal reflection, we shape and model the content of our reflection in diverse ways and learn from the process itself' (Moon 2004: 80). The process of reflection requires training and practice. Learning to reflect and to think intensely cannot be done without the appropriate contexts and procedures. Learning to make choices, to select and form our own opinions requires situations of experience, trial and error, supervision, evaluating and being evaluated or the possibility of self-correcting (McDonald 2016). Two components complement each other in the reflection process: experience and the mental activity that the individual performs upon it.

\subsection{Self-regulated learning}

Learning is conceived of here as a deliberate process that comes with the awareness of transforming conceptions and making meaning of something by selecting and assimilating new concepts. When students can manage their learning process, it implies that they have reached an elevated level of abstraction. There are not 
many students who can achieve this, as it demands an awareness of what is already known and an ability to determine goals related to what they would further like to know. Students need to be able to manage the connections between the different elements that are being learned to become self-regulated learners. Some researchers view self-regulation as a means to improve achievement and highlight the importance of setting goals in learning:

Self-regulated learning and performance refer to the process whereby learners personally activate and sustain cognitions, affects, and behaviours that are systematically oriented toward the attainment of personal goals. By setting personal goals, learners create selforiented feedback loops through which they can monitor their effectiveness and adapt their functioning. Because self-regulated persons must be proactive in order to set goals and engage in a selfregulatory cycle, supportive, motivational beliefs are also essential (Zimmerman \& Schunk 2015: 1).

For Agina, Kommers and Steehouder (2011) there are external factors, such as the resources and the pedagogical approaches used by the educators, which affect selfregulation. When they were researching how children talk and think while acting alone, they came to the conclusion that self-regulation can be increased without the need for the external intervention. According to Zimmerman's multi-level model, which represents the four stages in which students acquire their self-regulatory competency (observation, emulation, self-control and self-regulation), the portfolio method is a system that might help achieve such autonomous self-regulation (Zimmerman 2013). When students receive feedback, they are observing a social model. This observation, Zimmerman's first stage, involves the induction of the correct form of the skill. If the feedback directs students to re-examine and question their thoughts, this may help them to acquire the skill of reflection, which has been dealt with at length in 2.1. When the learner must duplicate the model, as in the case of peer feedback, they will be at the emulation stage, the second in Zimmerman's model. A self-controlled level of proficiency (the third) is attained when students master the use of skill outside the presence of the model (i.e., their teachers' feedback). This situation can be said to occur for example when they can engage in dialogues outside the educational context, are capable of argument and can search independently for reliable sources of information on a topic under discussion. At this level, students can be recognised as critical thinkers with the ability of making the right questions to understand and get deep into the problem or task.

At the fourth level, students gain the ability to self-regulate, which means they can adapt their performance to changing contextual conditions. It is at this level when students might be able to use multimodal elements to express their reflections and demonstrate their learning. The competencies gained during the last 
three levels allow them to step up forward with less guidance without compromising their performance.

Any teaching-learning system ultimately aims to lead the students to a selfregulation of learning. A self-regulated-learner, as has been shown, is a person who is aware of their learning process and who regulates the selection and the use of a diverse type of knowledge (metacognition), applies specific strategies to achieve academic goals and seeks to acquire knowledge and skills by themselves. In this sense, the portfolio method - understood as a scaffolding system - can be a tool that guides students towards the self-regulation of their learning.

\subsection{Feedback and feedforward}

Feedback is an essential component both of reflective and of self-regulated learning, as effective feedback enhances the students' learning when it leads to a deeper thinking process and helps to develop divergent thinking skills. As noted in 2.2, receiving and also providing feedback plays a particular role in the initial two stages of Zimmerman's four-stage model of the acquisition of self-regulation competences.

In general terms, feedback is a type of formative assessment designed to improve learning and guide students to examine their thoughts and understandings more closely. It provides students with information that confirms what they know which helps them transform their previous beliefs or knowledge (Nicol \& Macfarlane-Dick 2004). High-quality feedback that is meaningful and timely facilitates students' involvement with the learning environment and engages them in participating cognitively with the subject of study. It can strengthen the student's ability to self-regulate their learning process. The concept of formative feedback is based on the socio-cognitive perspective of learning and specifically on the notion of the Zone of Proximal Development (ZPD) coined by Vygotsky (Vygotsky \& Cole 1978). This zone determines the difference or distance that exists between what a person can do or develop individually and what they can achieve with the help of another. Building bridges between the learner and an expert adult or another experienced person involved in the learning process facilitates this development (Price et al. 2010).

If teacher feedback is grounded on positive and constructive comments which help the students restructure their ideas, if it is given soon after the learning event which is receiving feedback, and if the student perceives it as individualised, it can support to improve their learning in some ways, such as helping them see their strengths and weaknesses and it can also guide them towards critical thinking. Students would value comments positively when they feel it helped them to be confident about the task and when they think it could improve their understanding and performance. In some cases, it is essential for them to feel accompanied and guided in activities that are new for them, as in the case of reflection. As will be shown in 3.1, for instance, it is when students first begin developing their ePortfo- 
lios that they feel most insecure about whether they are reflecting in the right way, and here, the feedback process gains particular importance. As suggested by the concept of the ZPD, feedback can come from peers as well as teachers, and peer feedback is a further important component of self-regulated and reflective learning. Acquiring effective feedback skills requires practice, and this practice can be obtained by participating in peer-feedback activities.

While the feedback process plays an essential role in students' learning, feedforward must also be considered, as it focuses on future rather than on past experiences (Koen et al. 2012). Feedforward should be a complement of the formative feedback process through which students may know and understand the goals they must achieve (Duncan 2007). Sometimes we as teachers do not realise if students fail to completely understand the task we are asking them to do. Of course, the feedback process can guide them to reflect on it and in so doing reconsider their work or thoughts, but this occurs once the task has already been done. In the case of feedforward, teachers offer constructive guidance on how to do a task or on how it can be successfully completed. One way to give them this reinforcement is by using well-planned rubrics (Andrade 2000). Apart from describing the quality of performance at various levels via descriptors, these could include examples of achievement at various levels so that students can set their learning goals more effectively.

\subsection{Multimodality and its role in creating an ePortfolio}

In general, students have spent much of their formal education between two parallel worlds. The one within school has prioritised textual literacy, understood it as the one that promotes the reading and comprehension of printed texts and develops the ability to communicate ideas in written form. The other, outside school, has led them to negotiate images loaded with meaning contained in advertising, television and media, or the Internet, although they often lack the necessary skills to make a perceptive analysis of these elements. Written communication encompasses the transmission of a unique type of information with a grammar and a syntax specific of this format. During their schooling period, students have had to learn to decode symbols of written texts and make sense of the message conveyed with it, and in the same way, have developed skills needed to communicate using its symbols. Teaching should address new reading and communication skills that integrate a critical analysis of multimedia elements and in turn develop the ability of students to communicate through various modalities. As we live in a multimodal society, education must prepare students to use multiple languages and modes within an integrated approach of multiliteracies (Archer 2017).

If we analyse images of advertising posters or the content of a webpage, we might see that its elements contain different information from that which is in a written text. We would probably find that an image provides more information and includes different meanings than this written paragraph. Each modality specialises 
in transmitting information specific to that medium, but the combination of several modes can offer a wealth of meanings.

Thus, as visual literacy gains more importance in the digital age and students, in general, are familiarised with the consumption of multimedia content, we should lead them to embed writing in a wider semiotic frame (Archer 2017). On building their portfolio, they should feel free to utilise whatever tools they need (podcast, videos, drawings, digital narratives or comics) to represent their knowledge. It is here that the electronic portfolio (ePortfolio) plays a crucial role in education, due to its versatility in allowing students to collect learning evidence in different modes. During our research, we noted that many students struggled to represent their thoughts in a written mode. However, when they realised there were many ways of portraying their knowledge, the portfolio method reached its full potential. One of the most enriching formats that fostered student learning was when they had to build their portfolio through comics or graphic novels. Graphic novels or comics are means that combine visual contents with text, in sequence, to convey messages, ideas, thoughts and feelings (Kress 2013). The creation of comics engaged students in the task of reflection facilitating them to express their thoughts and nurturing their creativity.

\section{Learning through the Portfolio Method: the scaffolding process}

\subsection{First phase: reflective writing and teacher's feedback}

First-year students in many countries usually arrive at university with educational experience that has familiarised them with rote-type learning. In the last two years of high school, students have had to prepare for exams that will allow them to enrol at a university, and this learning system does not promote a reflection process. Usually, they have focused mostly on absorbing a vast amount of information without processing it. In contrast to this approach, the methodology of the portfolio involves a process of negotiation and action according to one's values and meanings.

When the students who participated in this project began their university studies, they had to document their learning in an ePortfolio system. This confronted them with a new task which required them to think in depth about what they had learned and how they had learned it. It was no longer a question of memorising facts, but of analysing their learning widely, evaluating actions and their consequences and confronting old beliefs with new ones (Hatton \& Smith 1995). During these four years of research, we could verify that students in general struggle to express their thoughts in a written mode. This might have two main reasons. First, they have never done this before and, second, previous tasks they had to do in high school before entering the university required them to write summaries of 
texts without analysing them in depth and without relating them with their previous knowledge. In general, these summaries represent a compendium of the main text topics. In some other cases, when teachers ask students to document their learning, they often describe facts and activities that occurred during sessions, making this a descriptive writing exercise instead of a reflection.

Documenting learning should be based on reflective writing with a clear and defined function for learning. It must go beyond writing about facts or making a diary of events and focus rather on the interpretation a person makes of their learning experiences according to a frame of reference which helps to understand them. The reflection that guides the reconstruction of thought is an activity that takes place internally in each person, which includes the ability to look at oneself, the self in front of others and at the surrounding world. To facilitate students' involvement in building their learning, teachers usually programmed activities aimed at favouring metacognition and the development of critical thinking by constant questioning. Doubt and uncertainty lead the students to search for answers, and this search, based on their previous experiences, is the beginning of reflective thought. An effective way of leading students through the reflective activity is by means of a reflective guide like the one shown in Table 1.

Table 1: Orientations to guide the students in the reflection task

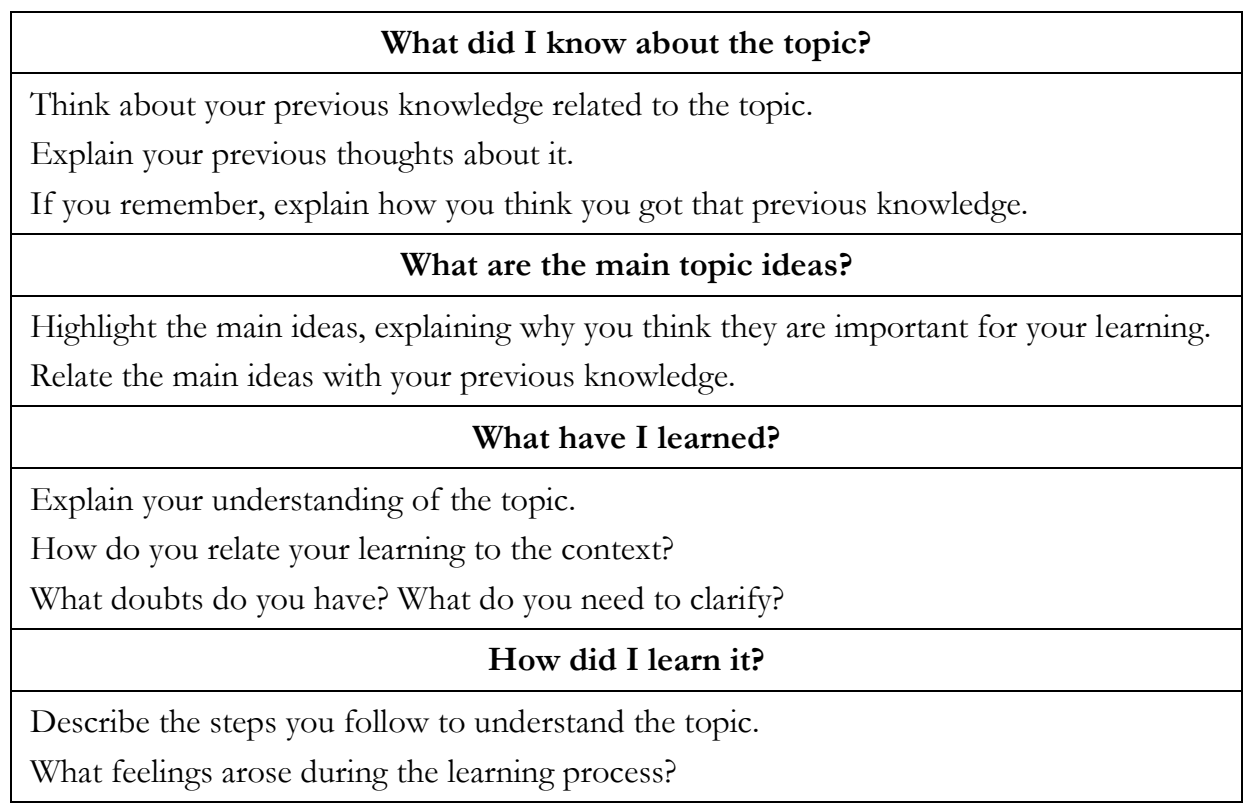

As noted in 2.3, supportive and constructive feedback was of particular value at this point, and we were able to gather data on the use of the portfolios and the corresponding efficacy and impact of the feedback. The students' portfolios were classified into three groups according to the frequency of their activity. Group one 
maintained a constant activity, uploading their reflections on the topics discussed or on the news commented on during the sessions. Students from this group searched for information related to the topic; then they attached it to their portfolio, making some comments around it. Some of them were able to relate the topics to incidents that occurred in their own surroundings. Some others questioned the news that we were analysing, and in doing so they demonstrated a critical thinking development. In group two, the students' activity remained irregular, with only a few artefacts uploaded. Group three students maintained insufficient activity with only a few or no contributions at all to their portfolio. The structured interviews that were carried out according to the number of artefacts and reflections uploaded allowed us to discover the reasons why groups two and three maintained so little or no activity. Most of the students from group two had a job, and they argued that they had too little time to carry out this time-consuming learning process. They made references to their previous years of schooling, in which a few days before the exam approached, they used to digest all the information they had received. Students from group three expressed feelings of fear and said they did not know exactly how they should construct their portfolio. Being an entirely new activity for them, many did not understand it. We then ran a seminar for them in which they could review examples of portfolios from other students and where they could read the reflections attached to them. As soon as we perceived activity in their portfolios, we gave them feedback.

The feedback that was provided for the students in group one was framed as constructive dialogues. In general, they received it positively, and it was observed that they valued it and analysed it, commenting on it later. The feedback given to group two did not have much impact on their learning as they didn't engage in a constructive dialogue process. They barely read it, and when they did, there was a time lapse between the activities and the reading of the feedback.

In analysing and classifying students' reflections (Table 2), we found that some of them remained at the level of describing facts. However, there were others who attempted to articulate connections between the reading texts, news and debates conducted during some classes that were related to the topic of study. Some other students started developing their thoughts, and although they were not of high complexity, they showed an attempt to provide a solution to a problem. Few students reached the reconstruction phase. At this level, the students learn to think by themselves, and this leads them to question how they know what they know. They can see themselves from a distance and reflect deeply. 
Table 2: Level of Reflections (based on Bain et al. 1999)

\begin{tabular}{|l|l|}
\hline \multicolumn{1}{|c|}{ Level of Reflection } & \multicolumn{1}{c|}{ Description } \\
\hline Describes facts & $\begin{array}{l}\text { Shows minimal topic understanding } \\
\text { No inferences }\end{array}$ \\
\hline Reports & $\begin{array}{l}\text { Expresses ideas in a superficial way } \\
\text { Portrays some feelings (anxiety, relief, fear) }\end{array}$ \\
\hline Starts a reflection process & $\begin{array}{l}\text { Finds meaning in the theory } \\
\text { Makes analysis to understand the theory }\end{array}$ \\
\hline Reconstruction & Emancipation \\
\hline
\end{tabular}

Despite all the advantages of the use of feedback in teaching, we must also add the caveat that in our experience not everything was smooth and therefore we recommend caution and suggest that one consider the following:

- Not all students desire feedback from their teachers.

- $\quad$ Feedback must be provided in a timely fashion. Otherwise, it will not help students reflect on their thoughts and so have no benefits.

- Sometimes students do not make use of feedback.

- In some cases, students take feedback as a criticism of their work.

As we had a considerable number of students enrolled in a subject, we decided that the right way to foster learning might be through a peer-feedback process. Taking into account Liu and Carless' (2006: 280) view of peer feedback as a "communication process through which learners enter into dialogues related to performance and standards" and noting Lundstrom and Baker's (2009: 31) definition of peer feedback as "the skill of being able to critically evaluate writing, defined as the ability to look at a classmate's writing and then provide effective feedback", we decided to start the second phase utilising this method.

\subsection{Second phase: peer feedback}

In the second year, students seem to be familiar with reflective writing and the feedback process. It is at this point when they can be trained to give feedback to each other. Peer feedback, in this phase, was an essential activity within the learning process. It was planned with the aim to enhance reflection and learning for both the critical friend and the receiver. When a critical friend provides constructive feedback, both learners benefit from seeing different views of a problem or task (Huisman et al. 2018). This constructive dialogue may serve to help restructure ideas and accumulate information and, if the feedback is of a high quality, it might help them to identify their strengths and weaknesses (Lundstrom \& Baker 2009). The interaction between students must be characterised by the exchange of 
ideas and must evaluate different points of view. If the feedback engages all participants in a constructive dialogue, all of them may have the opportunity to see the various positions of one problem and this might help them to assimilate and adjust information. Peers usually have different learning experiences and backgrounds; hence their cognitive structures may differ from each other's. The need to reach a consensus may lead them to radically rethink their ideas, thus overhauling cognitive structures. Only if students get involved in thoughtful and well-argued discussions, will they engage in a complex metacognitive process.

We asked the students to participate in the peer-feedback process voluntarily. After performing structured interviews to know about their willingness to participate, and before starting classes, we realised that not all the students were open to this initiative. Some students stated:

It overwhelms me to think that others are going to read my porffolio, it is probable that they do not agree with what I say.

I do prefer teacher feedback because it is the person who has experience.

I think I don't have enough experience to do it.

We decided to enrol those students who felt confident with the activity as we considered that their acceptance to participate in it might influence the peerfeedback efficiency and the way they got engaged in the task (Berndt et al. 2018, Huisman et al. 2018). The teacher's feedback remained the same as in the previous phase for those students who declined to get involved in the process, either because of fear or because they did not feel capable of carrying it out.

When analysing the students' interactions, we classified the peer-feedback activity as shown in Table 3.

Table 3: Peer-Feedback patterns

\begin{tabular}{|l|l|}
\hline \multicolumn{1}{|c|}{ Category } & \multicolumn{1}{c|}{ Definition } \\
\hline Superficial & $\begin{array}{l}\text { Feedback does not promote an exchange of ideas. } \\
\text { Dialogues are just approvals or disapproval of what is stated by the } \\
\text { peer. }\end{array}$ \\
\hline Dialogue & $\begin{array}{l}\text { There is no critical thought reflected in the dialogue amid students. } \\
\text { The arguments are not grounded on relevant or reliable texts. }\end{array}$ \\
\hline $\begin{array}{l}\text { Argumentative/ } \\
\text { Corrective }\end{array}$ & $\begin{array}{l}\text { There is an argument in favour or against interpretations, and } \\
\text { sometimes it points out errors or warns about possible } \\
\text { misinterpretations. } \\
\text { Seems to try to guide their peer to a deep thinking questioning } \\
\text { about their beliefs. }\end{array}$ \\
\hline
\end{tabular}

The superficial feedback might reflect a student's lack of willingness to interact for a further purpose than merely participating: this "just need to participate" attitude signals a lack of confidence in terms of facing interpersonal risks within the group. 
Such students may think that providing an argument against their peer's thoughts would incite a conflict. Some authors define this as a "lack of psychological security" (Dochy et al. 1999, Van den Bossche et al. 2006).

When a student feels more confident in themselves, they can give dialogical feedback. Even if they do not make informed judgments or express critical thoughts; this can be a good start in the feedback process. Some examples of dialogue feedback:

I can't imagine a library with shelves full of Ipads or electronic books. I can't imagine it without the aroma of old books or even new ones. Those books that have accompanied us since the beginning of history.

Feedback: The aroma will never disappear. Now we will have two shelves, one with the lifetime books and another with the electronic books, Ipads and more. What worries me is that our society can't find the balance.

In this case, the students started a dialogue. There is no specific issue but merely a concern, the topic is not analysed in depth, and there is no search for alternative information to continue and support the dialogue.

Although there were few cases in which peer-feedback reached the Argumentative/Corrective level, we could verify that the process benefited most of the participants in this process. They were engaged in an activity that helped them to create a web of ideas and thoughts which motivated them to share knowledge and led them to engage in further constructive dialogues.

\subsection{Third phase: producing arguments in multimodal form}

As noted in 2.4, there are compelling arguments for using multimodal formats in an ePortfolio and thus the students were encouraged to use any modes they chose, including visual and audio ones or combinations of them, to represent their learning process in their portfolios. Before starting the third phase, we conducted semistructured interviews which were audio recorded and subsequently transcribed. The interviews sought to explore the students' experiences with the ePortfolio process. Many of them expressed their preference for constructing their portfolio in a multimodal fashion, using podcasts, images or videos to capture their reflections and learning in a digital means:

Sometimes I struggle to express my thoughts and feelings in a written text, but I know that for me could be easy if I were allowed to express myself in an oral way.

When I am reading a text, I am drawing many images in my mind. I search for images that could express what I want to say.

The technology facilitates recording voices, making video scripts, attaching images to written text and many other possibilities. Students who use different modes to express their thoughts and learning must understand and competently control diverse forms of representation. Ideally, they need to know how to use audio, 
video, digital media and different kind of software. They also need to know how to use information judiciously, which implies the activation of high-level cognitive operations such as analysis, synthesis, reflection and knowledge reconstruction.

Having the freedom to express ideas, feelings, thoughts and reflections in a multimodal way, allows students to use the path that best suits their preferences. Communicating through images, scripts or digital stories does not mean that writing must be set aside, since it is a necessary competence for a person who is going to acquire a university education. Encouraging multimodal communication does however train students to produce arguments in multimodal form. But this is not an easy task, as Archer states:

Composing multimodal texts is also not a simple process. Composing is not just about selecting multimodal semiotic resources, but it is also about the weight given to each mode in a particular text. Often students write their own text but copy and paste the pictures. This prioritises the written mode and the visual gets relegated to the status of 'decoration' (2011: 377).

Before initiating the third phase, we provided students with training sessions on multimodal composition. In doing so, we aimed to eliminate barriers that could hinder them from communicating fluently using different multimedia elements. Thus rather than concentrating on the skills they needed, they could focus on their thoughts and how to construct a story which would express their reflections and knowledge.

When we started reviewing students' portfolios, we could verify a constant activity, much more frequent than in the previous phases. We cannot state with certainty that this was as a result of having the opportunity to use a multimodal language, since they had, at this point, more experience with the portfolios as they had in the first phase. However, the contributions were richer in terms of reflective depth and creativeness. 


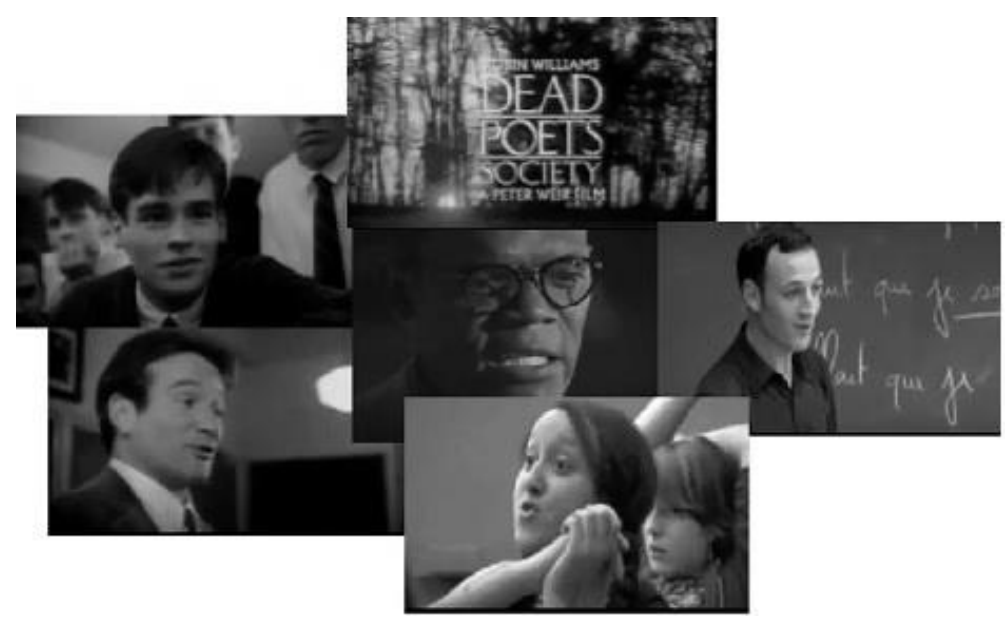

Figure 1: Using implicit knowledge and imagination. Film-scripts to express thoughts and reflections. Collage made from video-frames. (Source: http://aulapiccoline.blogspot.com/ 2013/04/la-educacion-en-el-cine.html [24.05.2019])

Some students engaged their mind's workbench in thinking on movies and expressed their thoughts and knowledge through film-scripts (Figure 1).

According to Seamon (2015), films can provide different stories and to build a coherent story using scripts; students need to carry out cognitive processes which involve utilising the implicit knowledge, and "effective learning and remembering enables us to imagine and plan the future [...]. Creating long-lasting memories involves attending to the meaning of an item or event and relating it to information already in memory" (Seamon 2015: 41).

Another student built up her portfolio by producing scripts created with avatars like the Sims $($ ) (Figure 2). She made a multimodal composition intertwining sound, music and semiotic structures, giving particular weight to each mode within the text to compose a story through which she narrated her learning and reflections.

The students' productions were diverse; some of them more creative and innovative than others, some of them presented a higher complexity than others. Most of them showed an excellent topic understanding, satisfactory knowledge development and an in-depth analysis of problems and cases. 


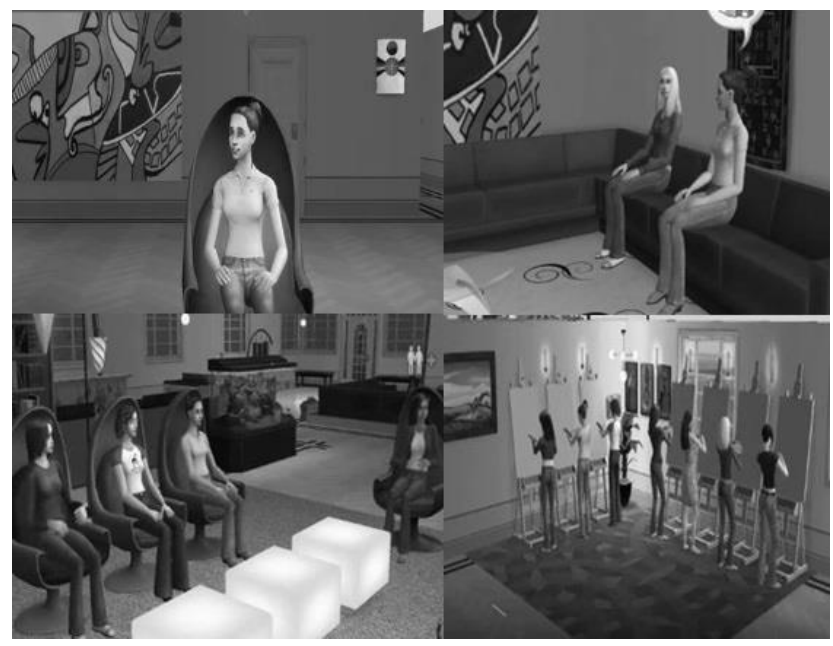

Figure 2: Script built up using avatars to express thoughts and demonstrate knowledge. Collage made from video-frames. (Source: http://aulapiccoline.blogspot.com.es/ [24.05.2019])

\subsection{Forth phase: using graphic narratives or comics towards a reflection process}

This phase was planned as the most challenging activity for the students. Creating a comic implies selecting essential elements for the narrative, choosing a perspective from which the reader could see it and determining symbols which would appear in each vignette. The author needs to find equilibrium between drawingcomposition and narrative coherence, bearing in mind grammatical elements and rhetoric. Students may be immersed in a deep-thinking process if they must make meaning of ideas which are implicit in text and images together (Berger 1971, Botzakis 2013, Meskin 2009).

To get to know students' readings habits they were asked to fill out an initial survey which helped us to draw each student's profile and shed some light on their attitude towards reading comics as well as previous experience in drawing and creating comics. Few of them said that they were fans of comics, and most of them had never read one before. To achieve the course aims, the students attended two seminars on comic design with an emphasis on the understanding of images, symbols and discourses. After the workshop, they began practical sessions focused on creating comics using different digital tools (Cartoon Story Maker, Make Belief Comix, Pixton, Powtoon and Toondoo). During two weeks, students were confronted to Francesco Tonucci's (2007) comics, which report the situation of traditional instruction, fixed in archaic methods and undemocratic educational practices. They had to analyse, discuss and interpret Tonucci's comics (Figure 3), redoing them afterwards using different scenes, examples and characters. 


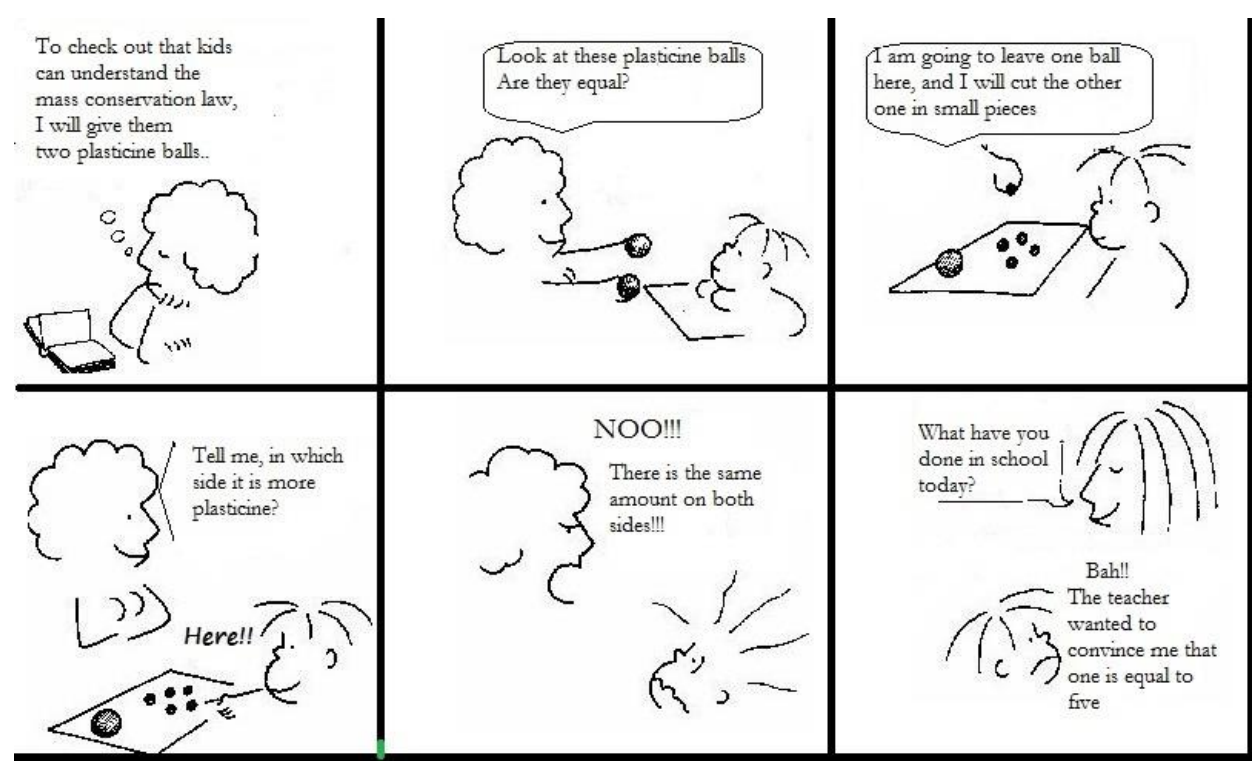

Figure 3: First Tonucci's cartoon read by the students (author's translation)

Reading Ayers and Alexander-Tanner's book (2010) was mandatory, as it is a teaching-related book designed as a comic. After reading some chapters, they had to reflect and discuss, in small groups, on school culture and the organisation of topics portrayed in it.

When the lecturer considered that the students had gained enough background to design comics, she gave them three educational issues, from which they had to choose one to create a comic. In creating their comics, the students had to demonstrate their understanding of the problem and propose ways to deal with it. Problems they had to solve can be outlined as 1) school as an organisation which claims to be equal for all the children and at the same time different for each one, 2) school as a heteronomous organisation which seeks to achieve children's autonomy, 3) school seeks to promote an education based on values, solidarity, peace and equality and at the same time it must prepare children for real life.

The students' graphic novels were analysed in terms of form and content. On examining the structure, we looked for essential elements of comics, such as frame, image, words and flow. As for the content, this being a process of great complexity since the students had to respond to educational problems by constructing a story, we sought for connections which demonstrated links with previous knowledge, news or themes related to the topic. We also analysed how information was synthesised and organised and how reflective learning was depicted. 

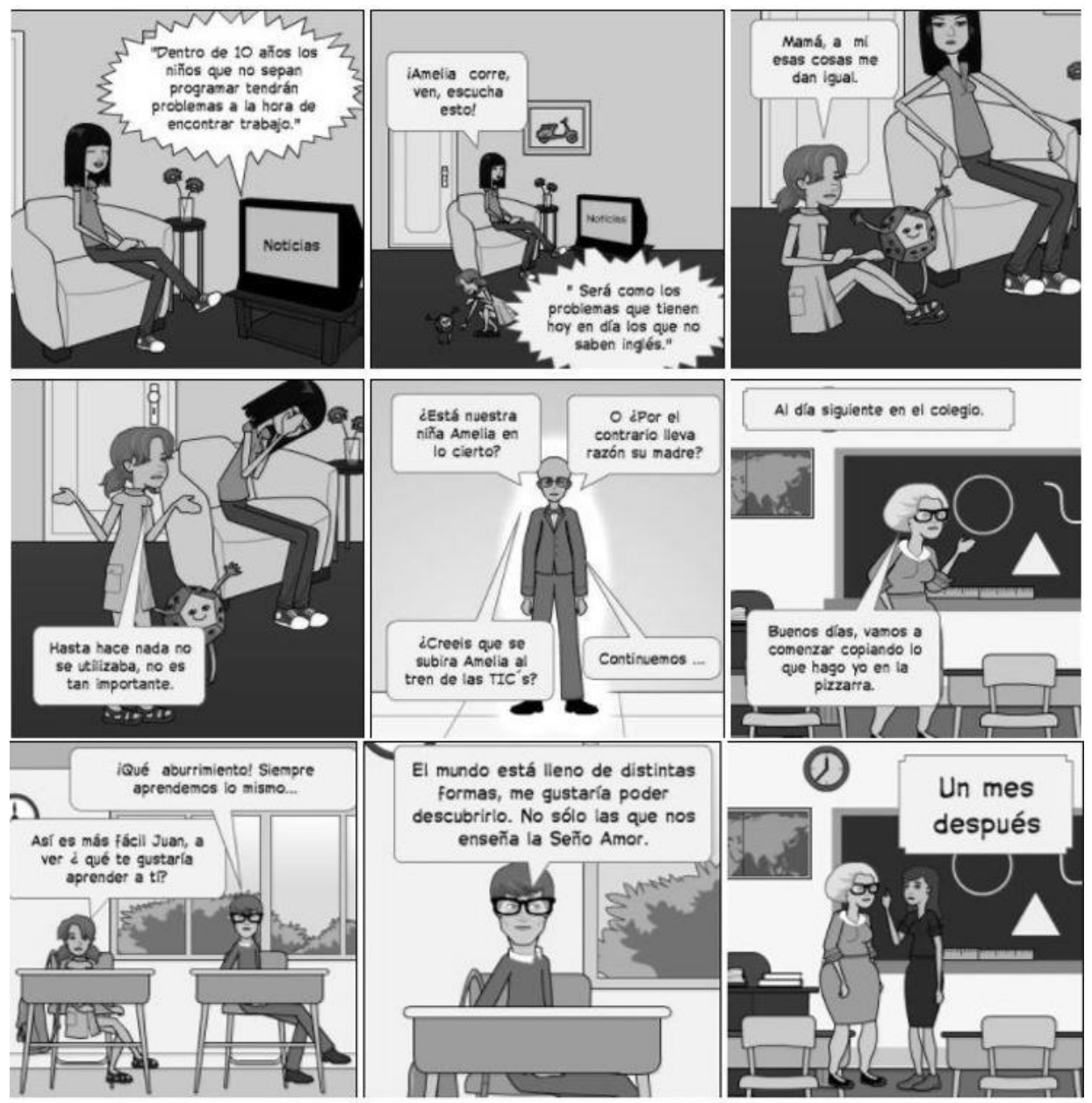

El mundo está lleno de distintas gustaría poder
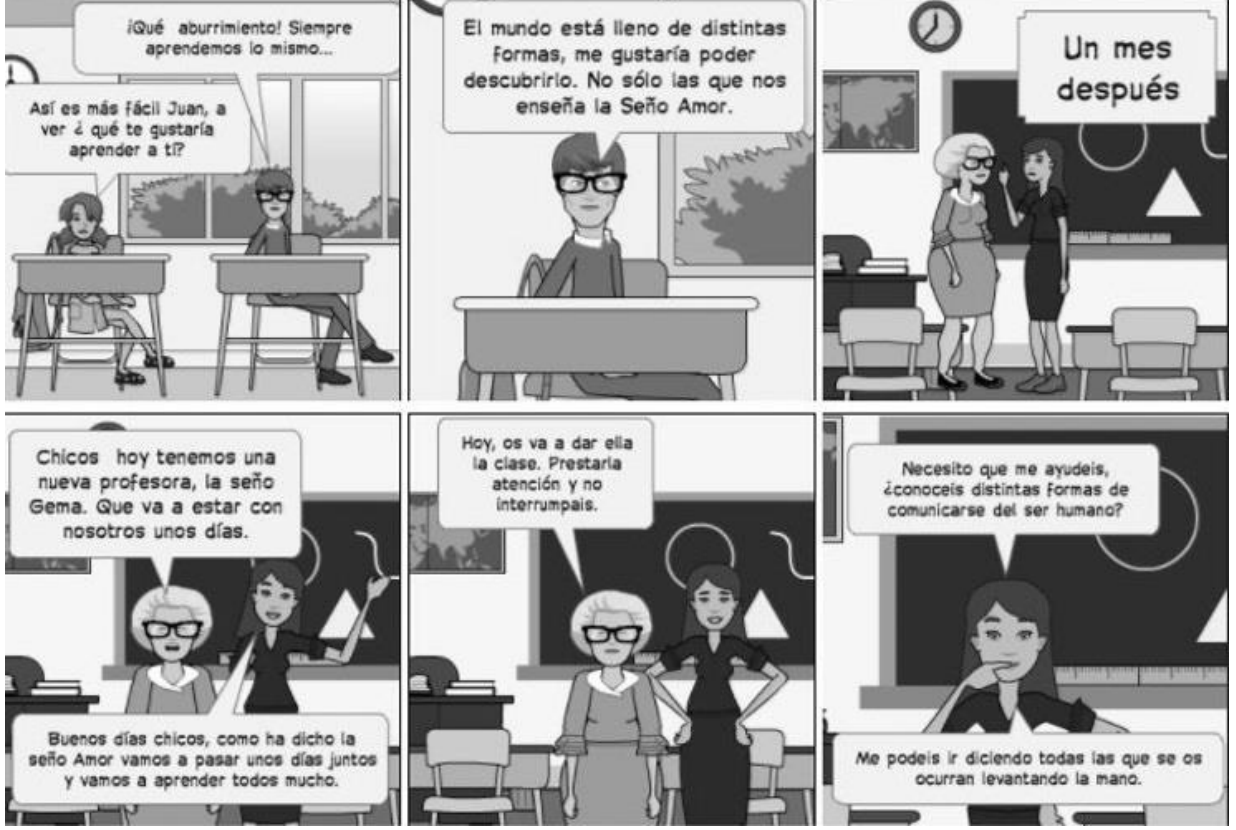

Figure 4: Student's comic. Reflection on the integration of technologies in school 
Some students created a hand-made comic, and some others used Toondoo or Pixton software. Apart from acquiring comic-making skills, they acquired knowledge of how to express their thoughts using this mode of expression. Some fragments of comics from students' ePortfolios are shown below. Figure 4 illustrates a real-life problem through which a student expressed her worry about the need to integrate technologies in education.

Although many people do not question that digital technologies are "good" for education, some other are reluctant to use it, thinking that they produce more "harm than good". In her story, the student reflected on this dilemma and left the reader to question it.

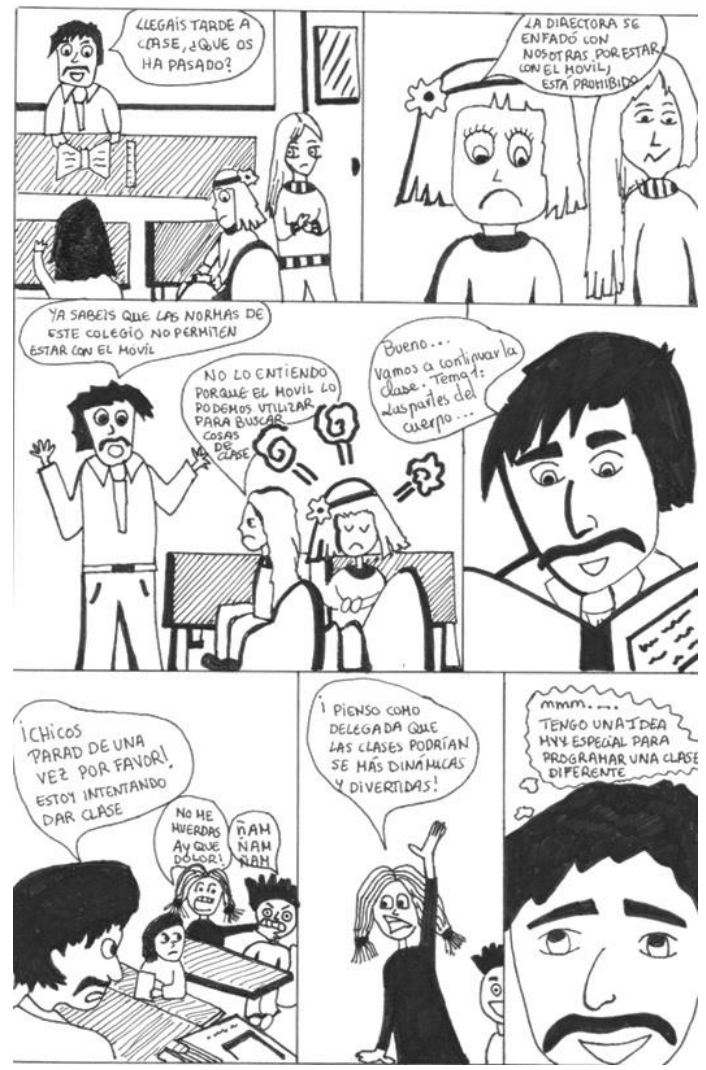

Figure 5: Fragment of a hand-made student's comic

Figure 5 shows a fragment of a hand-made comic through which a student explained how information technologies had influenced her life and why she considered the need to train teachers to integrate it into their classrooms. She explains through her comic that many teachers say it is important to use it in education, but sometimes it is just a "pose", as they feel they need to express a positive opinion. 
The fourth phase gave students the opportunity to express their knowledge and thoughts through comics. By the time they reached this phase, they had gained experience in reflecting on a problem or issue either by means of a written text or in a multimodal form.

\section{Conclusion}

There are many benefits of utilising the portfolio methodology within the teachinglearning process. Apart from representing an alternative to some reductionist assessment methods which value only the final product, it has the potential to promote holistic learning. The versatility of using different digital tools with which students document their progress, and the skills of reflection the method seeks to develop, foster critical-reflective, multimodal ways of learning.

In terms of metacognition, the portfolio method enhances self-directed learning. That is, students acquire the ability to examine themselves, their culture and environment; they will be able to develop the ability to take their own initiative, take responsibility for their learning and gain the ability to set their own goals.

However, the reflective activity is not an easy task. Therefore, it would be necessary to consider a feedback system to support this process. There could be barriers, such as the number of students, their inexperience with the reflective process, or fear or doubt about the potential of this activity. These barriers might prevent students from considering the portfolio methodology as a benefit for their personal development. Thus from our experience, in the context of higher education we suggest thinking of it primarily as a scaffolding process.

\section{References}

Agina, Adel; Kommers, Piet; Steehouder, Michael. F. (2011): The effect of the external regulator's absence on children's speech use, manifested selfregulation, and task performance during learning tasks. In: Computers in Human Behavior 27/3, 1118-1128.

Andrade, Heidi G. (2000): Using rubrics to promote thinking and learning. In: Educational Leadership 57/5, 13-19.

Archer, Arlene (2011): Clip-art or design: Exploring the challenges of multimodal texts for writing centres in higher education. In: Southern African Linguistics and Applied Language Studies 29/4, 387-399.

Archer, Arlene (2017): Using multimodal pedagogies in writing centres to improve student writing. In: Stellenbosch Papers in Linguistics Plus 53, 1-12.

Ayers, William; Alexander-Tanner, Ryan (2010): To Teach: The Journey, in Comics. London: Teachers College Press. 
Bain, John; Ballantyne, Roy; Packer, Jan; Mills, Colleen (1999): Using journal writing to enhance student teachers' reflectivity during field experience placements. In: Teachers and Teaching 5/1, 51-73.

Barrett, Helen (2010): Balancing the two faces of ePortfolios. In: Educação, Formação \& Tecnologias 3/1, 6-14.

Berger, Arthur (1971): Comics and culture. In: Journal Of Popular Culture V/1, 164-178.

Berndt, Markus; Strijbos, Jan-Willem; Fischer, Frank; Riley, Richard (2018): Effects of written peer-feedback content and sender's competence on perceptions, performance, and mindful cognitive processing. In: European Journal of Psychology of Education 33/1, 31-49.

Botzakis, Stergios (2013): Why I teach comics in higher education. In: Knowledge Quest 41/3, 68-70.

Dewey, John (1997): How we think. New York: Dover Publications.

Dochy, Filip; Segers, Mathieu; Sluijsmans, Dominique (1999): The use of self-, peer and co-assessment in higher education: A review. In: Studies in Higher Education 24/3, 331-350.

Duncan, Neil (2007): 'Feed-forward': improving students' use of tutors' comments. In: Assessment \& Evaluation in Higher Education 23/3, 271-283.

Hatton, Neville; Smith, David (1995): Reflection in teacher education: Towards definition and implementation. In: Teaching and Teacher Education 11/1, 33-49.

Huisman, Bart; Saab, Nadira; Van Driel, Jan; Van Den Broek, Paul (2018): Peer feedback on academic writing: undergraduate students' peer feedback role, peer feedback perceptions and essay performance. In: Assessment \& Evaluation in Higher Education 43/6, 955-968.

Hume, Anne (2009): Promoting higher levels of reflective writing in student journals. In: Higher Education Research and Development 28/3, 247-260.

Koen, Mariëtte; Bitzer, Elias; Beets, Peter (2012): Feedback or Feed-forward? A case study in one higher education classroom. In: Journal of Social Sciences 32/2, 231-242.

Kress, Günter (2013): Recognizing learning: A perspective from a social semiotic theory of multimodality. In: Saint-Georges, Ingrid de; Weber, Jean-Jacques (eds.): Multilingualism and Multimodality: Current Challenges of Educational Studies. Rotterdam: Sense Publishers, 119-140.

Liu, Ngar-Fun; Carless, David (2006): Peer feedback: The learning element of peer assessment. In: Teaching In Higher Education 11/3, 279-290.

Lundstrom, Kristy; Baker, Wendy (2009): To give is better than to receive: The benefits of peer review to the reviewer's own writing. In: Journal of Second Language Writing 18, 30-43. 
McDonald, Betty (2016): Improving Teaching and Learning Through Reflection. London: Lambert Academic Publisher.

Meskin, Aaron (2009): Comics as literature? In: British Journal of Aesthetics 49/3, 219-239.

Moon, Jennifer (2004): A Handbook of Reflective and Experiential Learning: Theory and Practice. New York: RoutledgeFalmer.

Nicol, David; Macfarlane-Dick, Debra (2004): Rethinking formative assessment in HE: a theoretical model and seven principles of good feedback practice. In: IEEE Personal Communications, 31. https://www.researchgate.net/publication/ 251777530_Rethinking_Formative_Assessment_in_HE_a_theoretical_model_ and_seven_principles_of_good_feedback_practice [26.06.2019].

Price, Margaret; Handley, Karen; Millar, Jill; O’Donovan, Berry (2010): Feedback: all that effort, but what is the effect? In: Assessment \& Evaluation in Higher Education 35/3, 277-289.

Rodgers, Carol (2002): Defining reflection: Another look at John Dewey and reflective thinking. In: Teachers College Record 104/4, 842-866.

Seamon, John (2015): Memory and Movies: What Films Can Teach us about Memory. London: The MIT Press.

Spalding, Elizabeth; Wilson, Angene (2002): Demystifying Reflection: A study of pedagogical strategies that encourage reflective journal writing. In: Teachers College Record 104/7, 1393-1421.

Tonucci, Francesco (2007): Frato, 40 años con ojos de niño. Barcelona: Graó.

Van den Bossche, Piet; Gijselaers, Wim; Segers, Mien; Kirschner, Paul (2006): Social and cognitive factors driving teamwork in collaborative learning environments: Team learning beliefs and behaviors. In: Small Group Research 35/4, 490-521.

Vygotsky, Lev; Cole, Michael (1978): Mind in Society: the Development of Higher Psychological Processes. Harvard University Press.

Wood, David; Bruner, Jerome; Ross, Gail (1976): The role of tutoring in problem solving. In: Journal of Child Psychology and Psychiatry 17/2, 89-100.

Zimmerman, Barry (2013): From cognitive modeling to Self-Regulation: A social cognitive career path. In: Educational Psychologist 48/3, 135-147.

Zimmerman, Barry; Schunk, Dale (2015): Handbook of Self-Regulation of Learning and Performance. New York: Routledge.

Zubizarreta, John (2009): The Learning Portfolio: Reflective Practice for Improving Student Learning. San Francisco: Jossey-Bass. 